\title{
IDH1(R132) Inhibitor IDH305
}

National Cancer Institute

\section{Source}

National Cancer Institute. IDH1(R132) Inhibitor IDH305. NCI Thesaurus. Code C121457.

An inhibitor of the citric acid cycle enzyme isocitrate dehydrogenase [NADP] cytoplasmic (isocitrate dehydrogenase 1; IDH1) with mutations at residue R132 (IDH1(R132)), with potential antineoplastic activity. Upon administration, IDH305 specifically inhibits IDH1(R132) mutant forms in the cytoplasm, which inhibits the formation of the oncometabolite 2-hydroxyg lutarate ( $2 \mathrm{HG}$ ). This may lead to both an induction of cellular differentiation and an inhibition of cellular proliferation in IDH1(R132)-expressing tumor cells. IDH1(R132) mutations are highly expressed in certain malignancies, including gliomas; they initiate and drive cancer growth by both blocking cell differentiation and catalyzing the formation of $2 \mathrm{HG}$. 